\title{
Hemodialysis or Transplantation for Ethiopia: A Cost Utility Analysis
}

\author{
Tariku Shimels ${ }^{1 *}$ and Arebu I Bilal ${ }^{2}$ \\ ${ }^{1}$ Medical Logistics and Pharmacy Service Coordination, Ethiopian Federal Police \\ Commission Health Service Directorate, Ethiopia \\ 2Department of Pharmaceutics and Social Pharmacy, School of Pharmacy, Addis Ababa \\ University, Ethiopia
}

\section{Research Article \\ Volume 2 Issue 1}

Received Date: November 29, 2018

Published Date: January 09, 2019

DOI: $10.23880 /$ aabsc- 16000112

*Corresponding author: Tariku Shimels, Medical Logistics and Pharmacy Service Coordination, Ethiopian Federal Police Commission Health Service Directorate, Addis Ababa, Ethiopia, Tel: 251-912471223; Email: tarphar2008@gmail.com

\section{Abstract}

Background: The burden of end stage kidney disease (ESKD) characterized with a requirement with lifesaving dialysis or kidney transplantation is estimated to be more than 1.4 million whereas the annual incidence exceeds $8 \%$ worldwide. In Ethiopia, there is no renal transplant practice whereas hemodialysis is characterized with very limited number of dialysis centers in the capital; Addis Ababa. The objective of this analysis was to evaluate the cost-utility of hemodialysis and renal transplantation in Ethiopia.

Method: A cost utility evaluation (CUA) was produced to estimate if kidney transplantation would be a cost-effective alternative to hemodialysis. The decision model was developed as a decision tree that allows for comparisons of costutility evaluation between the two alternatives. While a patient perspective was used in the study, The Probabilities cost of transplant and effects included in this study were derived from the literature following a formal MEDLINE search for studies published in English language.

Results: Transplantation resulted in an incremental cost of $\$ 42,623.74$ and incremental utility of 3.18 quality-adjusted life years (QALYs) compared with conventional hemodialysis presented with an incremental cost of $\$ 25,902.08$ but very less QALY of 0.36 over a five years' time horizon. Given its higher incremental costs, transplantation remained more cost effective than hemodialysis (ICUR of 13414.67 vs. 71860.00 \$ QALY). The one way ANOVA sensitivity analysis has also confirmed that the result of the CUA is not sensitive to any plausible parameter changes.

Conclusion: Our cost utility analysis result demonstrated that the incremental cost utility ratio of a patient's five year therapy by hemodialysis at end-stage renal disease is significantly higher than by performing therapy of kidney transplantation, by more than a factor of five times.

Keywords: Ethiopia, Cost utility analysis, Hemodialysis, Transplantation 
Acronyms and Abbreviations: ANOVA: Analysis Of Variance; CUA: Cost Utility Analysis; DKK: Denmark Krone; ESKD: End Stage Kidney Disease; ETB: Ethiopian Birr; EUR: Euro: FV: Future Value; Hosp.: Hospital; HRQoL: Health Related Quality of Life; ICE: Incremental cost Effectiveness; ICER: Incremental Cost Effectiveness Ratio; ICUR: Incremental Cost Utility Ratio; KT: Kidney Transplant; Lab. \& Invest.: Laboratory and Investigation; LYs.: Life Years; QALY: Quality Adjusted Life Year; QoL: Quality of Life; St.: Saint; US: United States

\section{Introduction}

The American journal of medical association defines kidney failure as a health condition that occurs when the kidneys cannot properly remove wastes which causes buildups of waste and fluid in the body [1]. Kidney disease and kidney failure, as one of the existing aforementioned health problems of either acute or chronic phase, are ever increasing, particularly in developing countries where the major underlying causes, diabetes and hypertension, are also on the rise. The global burden of end stage kidney disease (ESKD) characterized with a requirement with lifesaving dialysis or kidney transplantation is estimated to be more than 1.4 million [2] whereas the annual incidence exceeds $8 \%$ worldwide [3]. While the literature mentions several reasons behind, more importantly enumerated driving and leading factors include population ageing, type 2 diabetes mellitus and hypertension [2] for the development chronic kidney failure.

In Ethiopia, there is no renal transplant practice whereas hemodialysis is characterized with very limited number of dialysis centers in the capital; Addis Ababa, according to an observatory presentation by Philip [4]. We quoted the author's description as follows for the purpose of this topic.

“......During my trip I found that at Bethel Hospital, the cost of a dialysis treatment is about $\$ 100$ US. Because most of the people on dialysis are poor, this is a prohibitive cost. While rounding at the dialysis center, I saw many patients who only come to the dialysis center once a week because that is all their families can afford. Routine laboratory tests are not performed....."

The survival pattern of patients on maintenance hemodialysis in end stage kidney disease in Addis Ababa was analyzed by Tamiru [5]. As per the report, almost all of the patients were said to have a serum creatinine level of $>5 \mathrm{mg} / \mathrm{dl}$ and some degree of anemia at the time of dialysis initiation. Forty-one (45.1\%) deaths occurred during dialysis treatment and $21(23.1 \%)$ of patients died within the first 90 days of starting dialysis. Only $42.1 \%$ of them survived longer than a year. The study finally stipulated that hemodialysis is characterized by a high degree of mortality and an increasing demand for expenditures per life years gained. Additional factor to this problem on patients was also the lack of kidney transplantation as an alternative means of managing the kidney failure which in turn might arise because of the presumed high cost associated with acquisition of kidneys from a live donor and the procedure's complication.

Though there were no studies conducted on the cost utility evaluation of either alternative in Ethiopia, this paper is initiated to present a comprehensive understanding of costs as Dollar expenditures per consequences as Quality Adjusted Life Years gained in either scenario employing a combination of gross/microcosting document reviews and expert opinions for the hemodialysis in the country and literature sources from similar countries as well as other randomized clinical evidences for kidney transplantation.

\section{Method and Materials}

\section{Study Design}

A cost utility evaluation (CUA) was structured to estimate if kidney transplantation would be a costeffective alternative to hemodialysis in the context of Ethiopia. Accordingly, all relevant costs associated with the two alternative treatments were weighed against the effect of treatment. Economic evaluations such as CUA are usually employed to measure health outcomes in qualityadjusted life years (QALYs), which is a composite measure of health-related quality of life (HRQoL) and life expectancy [6].

While the study had incorporated both primary and secondary inputs from different sources, the result of the CUA is an incremental cost-effectiveness ratio (ICER), which is a common measure of the costeffectiveness/utility of transplantation versus hemodialysis [6]. To reach the objective of the study, we used a decision analytic model and the respective input parameters were analyzed using Microsoft-Excel accordingly.

\section{The Model}

The decision model was produced as a decision tree in order to allow for comparisons of cost-utility evaluation between the two treatment modalities; hemodialysis and kidney transplantation in Ethiopia. The model was fed 
with contextual findings through retrospective data, professional opinions, and literature on randomized studies for cost as well as health-related quality of life calculated for this purpose. As presented below (figure 1), the square decision node represents the choice between the two treatment options, hemodialysis and transplantation as replacement treatments of end stage kidney disease.

\section{Perspective and Time horizon}

For most of the health care expenditure in Ethiopia is covered by the patients' out of pocket payment which is also a fact in renal failure patients, this study considered a patient perspective to undertake the cost analysis so that all costs associated with the direct services and indirect expenses were included when possible to evaluate. In doing so, the study has also based its time horizon on an earlier finding in Ethiopia [5].

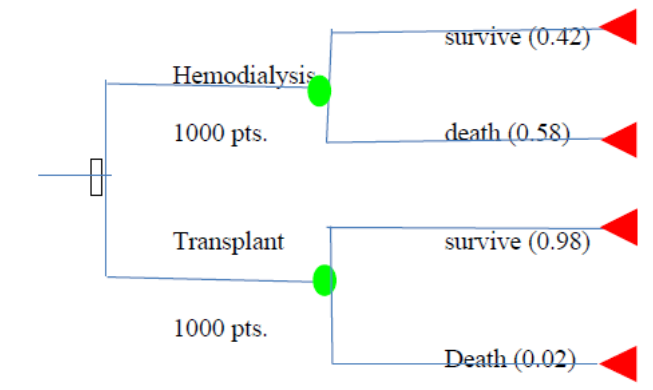

Figure 1: A decision tree for hemodialysis vs kidney transplant treatment.
As to this study, the first year survival among patients treated in St. Gabriel hospital was $42 \%$ and only one patient was survived the $6^{\text {th }}$ year. Therefore, we took a five year time horizon follow up based on the finding in order to picture up the real circumstance of hemodialysis in the country. We also used a similar horizon for transplantation taking a theoretical cohort of 1000 Patients.

\section{Input Values}

\section{Probabilities}

The Probabilities included in this study were derived from the literature following a formal MEDLINE search for studies published in English language. When no single study reported the exact probability of an event, an estimate was obtained by combining data from several sources. When multiple studies reported different probability estimates, the study or results that most closely represented the population of interest were chosen. (e.g., those that focused on an over 65-yr-old population, we also preferred to use the probability of dialysis first year survival 0.42 from the same context than the finding 0.902 we had by Rabat et al [7] of a developed economy context). If multiple studies were relevant, a mean value was calculated and used as the baseline estimate. While we apply other literature for transplantation, we used a study that reviewed documents of 2002 through 2010 retrospectively in St. Gabriel Hospital in the case of hemodialysis. Since there was no data on the probabilities of survival for the subsequent years, we assumed the first year survival figure throughout the next four years (Table 1).

\begin{tabular}{|c|c|c|}
\hline Description of parameters & Estimates/year & Sources \\
\hline \multicolumn{3}{|c|}{ Probabilities } \\
\hline Probability of death from transplant & 0.02 & {$[8]$} \\
\hline Probability of survival from dialysis & 0.42 & {$[5]$} \\
\hline Costs of Dialysis & & \\
\hline Dialysis service & $\$ 10,830.70$ & Records \& professionals interview in St. Gabriel Hospital \\
\hline Medications & $\$ 1,058.54$ & {$[9]$} \\
\hline Supplies during/ after session & $\$ 280.80$ & {$[9]$} \\
\hline Staff and card & $\$ 492.30$ & Records \& professionals interview in St. Gabriel Hosp. \\
\hline Laboratory tests and investigations & $\$ 245.80$ & Records \& professionals interview in St. Gabriel Hosp. \\
\hline Indirect non- medical costs of dialysis & $\$ 12,468.00$ & {$[10]$} \\
\hline Costs gone to non- survived (dead) & $\$ 8,374.13$ & {$[5]$} \\
\hline Total dialysis related costs & $\$ 33,750.27$ & \\
\hline & Costs of Transplantation \\
\hline Procedure & $\$ 7,826.09$ & {$[9]$} \\
\hline Costs of acquisition from live donor & $\$ 24,152.00$ & {$[11]$} \\
\hline Investigations & $\$ 286.96$ & {$[9]$} \\
\hline
\end{tabular}




\section{Annals of Advanced Biomedical Sciences}

\begin{tabular}{|c|c|c|}
\hline Medications & $\$ 6,712$ & {$[9]$} \\
\hline Indirect transplant costs and loses & $\$ 6,188$ & {$[12]$} \\
\hline Costs of death during transplantation & $\$ 0$ & Assumption \\
\hline Totals of transplantation related costs & $\$ 45,165.05$ & \\
\hline \multicolumn{3}{|c|}{ Utilities } \\
\hline Utilities associated with dialysis & 0.49 & {$[13,14]$} \\
\hline Utilities associated with transplantation & 0.78 & {$[13,14]$} \\
\hline
\end{tabular}

Table 1: Different parameters and their respective annual estimates for hemodialysis and transplantation from different sources, March, 2014.

\section{Valuation of Costs}

Direct Costs: the data on direct costs for hemodialysis care, including the dialysis service per session, laboratory and other investigations as well as overhead costs paid in forms of service and card charges, were obtained from the records and professionals' opinion in St. Gabriel general hospital. Since it was difficult to estimate the costs of medications used and the costs of supplies consumed during/after dialysis, we relied to take the costs reported from Sudan [9]. The costs for hemodialysis service is computed based on the current minimum price of 2200 Ethiopian Birr (112.8 USD) per session per patient on a twice per week basis. The service and card charges were calculated based on 100 Ethiopian Birr (5.13USD) per patient per visit. Laboratory and investigation costs were computed based on the range of charges reported from the hospital (30-70 ETB). We used the average 50 ETB (25.64 USD) per patient per session to compute the annual value. The data for the direct costs of transplantation including procedure, acquisition from live donor, investigations and medication were taken from the literature most of which are from Sudan for the purpose of this evaluation. The cost of acquisition from live donor was based on a USD of 1999 and was adjusted to a 3\% of its future value (FV) in the present study. To calculate the costs gone to deceased patients in hemodialysis, we used a proportional estimate based on the finding in Ethiopia [5]. According to the study, the annual mortality was $58 \%$ (53 of 91 people) of which 39.6\% (21 of 53 deaths) occurred within the first 90 days of starting hemodialysis. As the three months mortality was less than the median value, we assumed additional deaths of $10.4 \%$ deaths (nearly 5-6 deaths) in the coming one month for a four month median time of $50 \%$ deaths (26-27 patients). This results in a one third (i.e.33.3\%) of the resource utilized in a survived patient will go to dead patient. Costs used for any estimate in Ethiopia were converted to a USD based on the time's exchange rate (1USD=19.5 ETB).

Indirect costs; Indirect costs were calculated from an estimation of lost spare time on the part of patients and relatives, an estimation of lost working time on the part of relatives, and home care. For hemodialysis as these considerations were difficult to calculate from our setting, we took findings in other studies assuming a uniform recurrence for the treatment of evaluation is health facility based (in center hemodialysis) that requires a whole course of indirect expenditures. We didn't take in to account of productivity losses of patients associated with the hemodialysis treatment. Because, there is no difference on productivity in whether or not the patient goes to hospital to treatment and the mere lose is due to the illness. The indirect costs and loses of productivity during transplantation were computed based on a result of 6 months in the literature [11].

\section{Utilities}

Many studies agree that changes in RRT alternative are likely to result in changes in better survival and health related quality of life, particularly in the case of kidney transplant. Therefore, quality-adjusted life years (QALYs) along with its intrinsic life years saved will be the important parameter of health outcome considered in this study for comparison. The QALY is multidimensional health outcome which combines patient survival and QoL; QoL measured on an interval scale from 0 (worst health) to 1 (full heath). The results of the cost-effectiveness analyses are expressed as the incremental cost per LYS or per QALY gained of proposed modality changes, compared with current clinical practice. The respective scores of QoL mentioned in table 1 are time trade off utilities obtained from other studies [15] and are also discounted over the coming four years of the study.

\section{Discounting of Costs and Effects}

We discounted the costs and effects based on the unit values and annual calculation presented in table 1 above. Taking the theoretical cohort of 1000 patients for each alternative, we computed the resources gone per years of survival. For example in hemodialysis, we have 420 survived patients the first year, 176 patients the second year and the likes for $58 \%$ of each year's patients die at nearly a median time of the fourth month of the year. 
Costs and effects are assumed to accrue in the same fashion along each survived patient in the years. Presented finally is the average costs and benefits per patient. As can be seen in table 2 below, the costs and benefits that would be incurred and obtained the coming four months in each scenario are seen to be discounted to present values in order to have a clear observation of the unforeseen changes. The first year is not discounted as the analysis assumes an annuity due (costs and effects occurring the beginning of each year) which applies to the subsequent four years.

\begin{tabular}{|c|c|c|c|c|c|c|c|c|c|c|}
\hline \multicolumn{5}{|c|}{$\begin{array}{c}\text { Costs of Dialysis For Five Consecutive } \\
\text { Years In \$US }\end{array}$} & \multirow[b]{2}{*}{ Medication } & \multirow[b]{2}{*}{$\begin{array}{l}\text { staff \& } \\
\text { card }\end{array}$} & \multirow[b]{2}{*}{$\begin{array}{l}\text { Lab. \& } \\
\text { invest. }\end{array}$} & \multirow[b]{2}{*}{$\begin{array}{l}\text { Indirect } \\
\text { costs }\end{array}$} & \multirow[b]{2}{*}{$\begin{array}{c}\text { costs in } \\
\text { dead }\end{array}$} & \multirow[b]{2}{*}{$\begin{array}{l}\text { Total dialysis } \\
\text { related costs }\end{array}$} \\
\hline Year & Survived & Dead & $\begin{array}{c}\text { dialysis } \\
\text { ser. }\end{array}$ & Supplies & & & & & & \\
\hline 0 & 1000 & & & & & & & & & \\
\hline 1 & 420 & 580 & 4548894 & 117936 & 444586.8 & 206766 & 103236 & 5236560 & 4856995 & 15514974 \\
\hline 2 & 176 & 244 & 1854889 & 48090.41 & 181287.8 & 84312.35 & 42096.23 & 2135296 & 1980522 & 6326494 \\
\hline 3 & 74 & 102 & 756362.4 & 19609.68 & 73923.19 & 34379.79 & 17165.45 & 870703.4 & 807591.7 & 2579736 \\
\hline 4 & 31 & 43 & 308419.6 & 7996.18 & 30143.44 & 14018.94 & 6999.51 & 355044.1 & 329309.2 & 1051931 \\
\hline \multirow[t]{3}{*}{5} & 13 & 18 & 125763.3 & 3260.58 & 12291.5 & 5716.46 & 2854.17 & 144775.3 & 134281.4 & 428942.7 \\
\hline & Total & & 7594328 & 196892.9 & 742232.8 & 345193.6 & 172351.4 & 8742379 & 8108700 & 25902078 \\
\hline & \multicolumn{2}{|c|}{ per Patient } & 7594.33 & 196.89 & 742.23 & 345.19 & 172.35 & 8742.38 & 8108.7 & 25902.08 \\
\hline \multicolumn{4}{|c|}{$\begin{array}{c}\text { Costs of transplant in five years in } \\
\text { \$US }\end{array}$} & & & & & & & \\
\hline Year & Survived & Dead & $\begin{array}{l}\text { Proced } \\
\text { ure }\end{array}$ & \multicolumn{2}{|c|}{ kidney acquisition } & & $\begin{array}{c}\text { Investigati } \\
\text { on }\end{array}$ & medications & $\begin{array}{c}\text { indirect } \\
\text { costs }\end{array}$ & $\begin{array}{c}\text { Total transplant } \\
\text { costs }\end{array}$ \\
\hline 0 & 1000 & & & & & & & & & \\
\hline 1 & 980 & 20 & 7669568 & 23668960 & & & 281220.8 & 6577760 & 6064240 & 44261749 \\
\hline 2 & 960 & 20 & - & - & & & 267569.3 & 6258451 & & 6526021 \\
\hline 3 & 941 & 19 & - & - & & & 254580.5 & 5954643 & & 6209223 \\
\hline 4 & 922 & 19 & - & - & & & 242222.2 & 5665583 & & 5907805 \\
\hline 5 & 904 & 18 & - & - & & & 230463.9 & 5390554 & & 5621018 \\
\hline & Total & & 7669568 & 23668960 & & & 1276057 & 29846991 & 6064240 & 68525816 \\
\hline & \multicolumn{2}{|c|}{ per Patient } & 7669.57 & 23668.96 & & & 1276.06 & 29846.99 & 6064.24 & 68525.82 \\
\hline \multirow{2}{*}{\multicolumn{3}{|c|}{\begin{tabular}{l|l|}
\multicolumn{2}{c|}{ Utilities in quality adjuste } \\
Year & survived of dialysis
\end{tabular}}} & ed life year & rs in five ye & ears of the $r$ & espective al & ternative & & & \\
\hline & & & \multicolumn{2}{|c|}{ Discounted QALYs } & & \multicolumn{2}{|c|}{$\begin{array}{c}\text { Survived of } \\
\text { Transplantation }\end{array}$} & \multicolumn{2}{|c|}{ Discounted QALYS } & \\
\hline 0 & 1000 & & & & & 1000 & & & & \\
\hline 1 & 420 & & 205.8 & & & 980 & & 764.4 & & \\
\hline 2 & 176 & & 94.19 & & & 960 & & 745.94 & & \\
\hline 3 & 74 & & 38.41 & & & 941 & & 709.73 & & \\
\hline 4 & 31 & & 15.66 & & & 922 & & 675.28 & & \\
\hline 5 & 13 & & 6.39 & & & 904 & & 642.5 & & \\
\hline \multicolumn{2}{|c|}{ Total QALYs } & & 360.45 & & & & & 3537.85 & & \\
\hline per & r patient & & 0.36 & & & & & 3.54 & & \\
\hline
\end{tabular}

Table 2: Discounting Of Costs and Effects (Assuming A Discounting Rate Of 3\% Per Year \& Annuity Due /Zero In Year One).

\section{Sensitivity Analysis}

Sensitivity analysis determines the level of uncertainty in the components of the evaluation by repeating the comparison between cost items and consequences while varying the assumptions underlying the estimates. We conducted a one-way sensitivity analysis varying one health state probability, cost item or health related quality of life at a time while others are held at base value to measure its impact on the results of the evaluation [6]. 
The analysis was repeated the for the significant parameters as; survival from hemodialysis, costs of hemodialysis service for a single session, indirect costs of hemodialysis, medication costs of hemodialysis, medication costs of transplantation, QALYs gained in hemodialysis and QALYs gained from transplantation. The changes made in the sensitivity analysis were based on two alternative considerations. One based on the lowest or the highest value reported, and a randomly plausible ranges of estimates for costs, effects or probabilistic uncertainties which could arise as a result of variations between results in different countries.

\section{Results}

\section{Base Case}

Transplantation resulted in an incremental cost of $\$ 42,623.74$ and incremental utility of 3.18 qualityadjusted life years (QALYs) compared with conventional hemodialysis presented with an incremental cost of $\$ 25,902.08$ but very less QALY of 0.36 (Table 3 ) over a five year time horizon. Given its higher incremental costs, transplantation remained more cost effective than hemodialysis (ICUR of 13414.67 vs. 71860.00 \$/QALY).

\begin{tabular}{|c|c|c|c|c|c|}
\hline & Costs (\$) & Outcome (QALYs) & Incremental cost & Incremental outcome & ICUR(\$ /QALY) \\
\hline Nothing to be done & 0 & 0 & $\ldots$ & $\ldots$. & $\ldots$. \\
\hline Hemodialysis & $\$ 25,902.08$ & 0.36 & $\$ 25,902.08$ & 0.36 & 71860 \\
\hline Transplantation & $\$ 68,525.82$ & 3.54 & $\$ 42,623.74$ & 3.18 & 13414.7 \\
\hline
\end{tabular}

Table 3: Results for Incremental Cost Utility Ratio (ICUR).

Shown below (Figure 2) is the alternative presentation of the above tabular results in to a clearly comparable scatter plot. From the graph, it is possible for a healthcare decision maker to comprehend that hemodialysis is initially characterized by a relatively lower cost (of \$25902.08) than transplantation (\$ 68525.82) but also resulting in lower overall QALYs (of 0.36 QALY) than which can be obtained through transplantation (3.54 QALY). When we compare the incremental changes in cost of each treatment option to the incremental changes to their QALY, we will note the same value for hemodialysis which is an increment from do nothing and no cost and a slight lower cost figure of transplantation $(\$ 42,623.74)$ than the original but still higher than hemodialysis. The rate limiting changes happen when one computes the incremental cost effectiveness/ utility ratio. As illustrated in figure 2, the ICUR of transplantation is found with a dramatically lower cost per units of QALY obtained (\$13414.67) as compared to hemodialysis (\$71860.00). Hence, transplantation is by far dominant alternative.

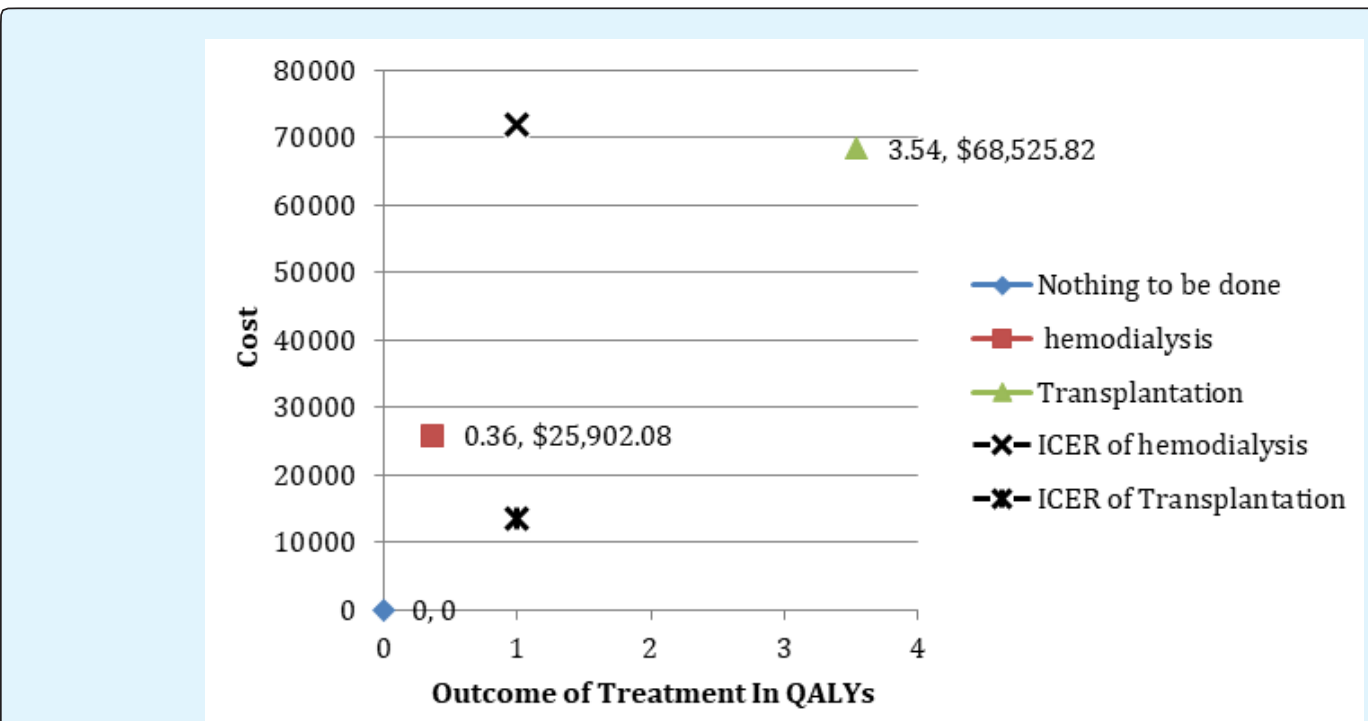

Figure 2: Graph showing ICERs and cost to QALY obtained through hemodialysis and transplantation. 


\section{Sensitivity Analysis}

When the robustness of the evaluation result was tested by introducing estimates for the aforementioned significant parameter uncertainties, the results of the one way ANOVA showed that transplantation is still the dominating treatment in all perspectives. This indicated that the result of the CUA is not sensitive to any plausible parameter changes (Table 4). The optimistic variation of particular parameters still resulted in a $100 \%$ dominance of transplantation.

\begin{tabular}{|c|c|c|c|c|}
\hline Variable & $\begin{array}{c}\text { Parameter } \\
\text { value }\end{array}$ & Incremental cost & $\begin{array}{c}\text { Incremental } \\
\text { effect }\end{array}$ & Incremental cost utility ratio \\
(\$/QALY)
\end{tabular}

Table 4: One way ANOVA sensitivity analysis.

Tran: Stands for Transplant; Transplantation dominates indicates that Transplant leads to greater benefit at lower cost than hemodialysis.

As displayed in the sensitivity graph below (Figure 3), The ICUR of hemodialysis is projected to 191151USD per QALY when the probability of survival is reduced by $75 \%$.
For most of other parameter changes, the cost is below $\$ 100000$ whereas transplantation remains under $\$ 20000$.

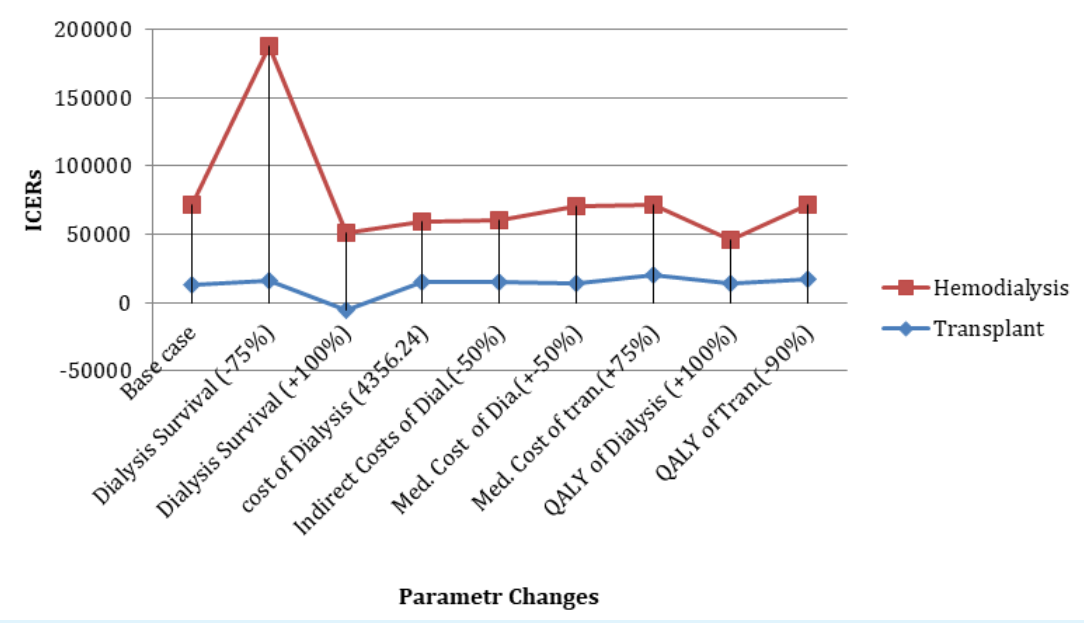

Figure 2: Sensitivity Analysis graph for hemodialysis vs. transplantation treatments. 


\section{Discussion}

The cost utility analysis of this study shows that transplantation is cost effective as compared to hemodialysis. The finding is also in concordance with reports from many literature review studies [16-18]. While the results were computed based on patients' perspective, overall per patient costs in the five year follow up and incremental costs of hemodialysis were lower compared to transplantation. However, the dominance of transplantation is distinct due to its contribution in higher QALYs. Among the theoretical 1000 cohort of patients considered in the analysis, 13 and 904 survived the $5^{\text {th }}$ year in hemodialysis and transplantation respectively. Though Costs were allocated with patients gone to death in hemodialysis at median time of $4^{\text {th }}$ month while it was assumed at the beginning of each year for transplantation, dominance of transplantation was realized mainly due to lower reported annual mortality and better health related quality of life (HRQoL).

This analysis presents an important awareness on comparative treatment modalities of end stage renal disease. Since the problem is growing worldwide being a double burden in the third world, policy makers are expected to consider and avail cost effective treatment strategies from both government as well as societal perspectives. Evaluated alternatives in the present study were hemodialysis and kidney transplantation of which the former is under practice in Ethiopia while the latter is totally not. As technological advancement comes more and the problem requires more attention in quality of life and increased life expectancy, this piece of evidence is supposed to convince the healthcare providers of Ethiopia that the present means is not reliable including its very limited accessibility. Our finding is good in that it revealed that transplantation is a more cost effective alternative while at the same time provides higher QALY despite its initial higher costs in acquisition and complications of rejection.

Given the fact that transplantation dominates hemodialysis in this study, specific variations exist when the costs and effects of each option is compared to the literature having the same conclusion. Our analysis results are much lower than those by a study In Den Mark; a six year follow-up evaluation revealing a 190,504.02 USD for hemodialysis and 149,483.47USD [16]. One possible reason for the difference might be due to the methodology used. While we applied a pure decision tree which didn't consider any transition from one health state to another health state, the study in Den mark was based on a Markov based decision tree which may precisely estimate varied costs during treatment switches (hemodialysis to transplantation and transplantation to hemodialysis) in addition to the differences in time horizon and socio-economy. The average annual cost saving from transplantation in the present analysis $(58,445.33$ USD in five years) is also lower than the same study in Serbia [17] which reported 181,975.68 USD per QALY in a period of 10 years. Justifications for this would also be from higher hemodialysis costs, higher utilities from transplant leading to a decreasing marginal cost in the subsequent years or even lower costs for acquisition from donor and other indirect expenses in Serbia than those used in this analysis.

The total per patient cost estimate of hemodialysis determined in this evaluation was significantly higher than the same figure in Sudan [9]. Typical variation is for hemodialysis service and indirect costs of patients and families' productivity loses associated with treatment follow up. The instrument costs were lower in Sudan mainly because the study used a public hospital. Indirect and direct no medical costs were included in the present evaluation as in-center hemodialysis demands more expenses through a caregiver and frequent health facility visit. The discounted first and five year survival from transplantation used in this evaluation (98 \% \& 91.3\% respectively) were comparably similar but slightly higher than a report in India (93\% \& 83.3\% respectively) [19]. Whereas the rest of inputs in the transplantation were also adopted from Sudan purposefully, both direct and indirect costs lie within a range of estimates in a developing context [20].

Our cost utility analysis result demonstrated that the incremental cost utility ratio of a patient's five years therapy by hemodialysis at end-stage renal disease is far greater than by performing therapy of kidney transplantation, by more than five times. The difference is magnified by not based on hemodialysis costs but due to higher contribution to quality adjusted life year (QALY) both in quality and life expectancy of transplant treatment than hemodialysis [21-23].

The cost and probability estimates of transplantation in this analysis were merely based on available published evidences and were used to model the evaluation since the practice is not common in this country. Therefore, it is possible that some data relating to specific resources use may not be completely representative of current clinical practice in most of the developing nations, although significant prices have been updated to timely US dollars. In addition, the evaluation didn't take in to consideration of costs relating to co-morbidities such as diabetes, 
ischemic heart disease and cancer in both scenarios. It is likely, hence, that incorporation of these other costs would further substantiate the economic benefit of increasing the transplant rate despite the same results in the present assumption. A major advantage of transplantation over hemodialysis is that health is generally improved in recipients to an extent that physical function approaches normal [24-27]. However, the costs used in this study might be likely to be underestimated since we didn't incorporate costs of transplant rejection, complication, or costs gone to death. Nor did this evaluation assumed switches among different treatments (hemodialysis to transplant and vice versa). We also assumed constant costs and effects discounted annually among patients in both treatments throughout the five years. The probability of survival in the hemodialysis group was taken from a 2013 retrospective study in Ethiopia [5]. Though we used this lower figure for the validity of this study, generalizability in other similar countries might be suffered. Finally, it is worth to mention that this evaluation is limited to only two generic alternatives of treating end stage kidney disease in Ethiopia; in-center hemodialysis and live donor transplantation. Other variations such as; peritoneal dialysis, home based hemodialysis; satellite hemodialysis and transplant from a deceased donor were not considered at all.

\section{Acknowledgment}

We wish to forward our deepest gratitude to all nephrology unit staffs of St. Gabriel general hospital for their unreserved support and cooperation in this study. We also want to thank Addis Ababa University for allowing us to use its library resources in pursue of the evaluation. Last but not least we would like to give special thanks to Dr. Petros Pechlivanoglou and Ato Eskinder Eshetu for their invaluable support in this study.

\section{References}

1. Lise MS (2009) kidney failure. Journal of Amarican Medical Association 301(6): 686.

2. Moeller S, Gioberge S, Brown G (2002) Global overview of patients, treatment modalities and development trends. Nephrol Dial Transplant 17(12): 2071-2076.

3. Schieppati A, Remuzzi G (2005) Chronic renal disease as a public health problem: epidemiology, social, and economic implications. Kidney Int Suppl (98): S7-S10.
4. Philip J Juso (2009) Renanal replacement therapy in Ethiopia. The Permanente Journal 13.

5. Tamiru S, Esayas Kebede Gudina, Belete Habte, Amare Deribew, Tewodros Agonafer, et al. (2013) Survival patterns of patients on maintenance hemodialysis for end stage renal disease in Ethiopia: summary of 91 cases. BMC Nephrology 14: 127.

6. Drummond MF, Sculpher MJ, Torrance GW (2005) Methods for the economic evaluation of health care programs. 3rd ed. New York: Oxford University Press Inc. J Epidemiol Community Health 60(9): 822-823.

7. Rabbat CG, Thorpe KE, Russell JD, Churchill DN (2000) Comparison of mortality risk for dialysis patients and cadaveric first renal transplant recipients in Ontario. Canada. J Am Soc Nephrol 11(5): 917-922.

8. Canadian Institute for Health Information (1999) Annual Report, Dialysis and Transplantation, Canadian Organ Replacement Register. Ontario, Ottawa.

9. Mohammed E, Elham E, Waheeb G (2010) Costs of Hemodialysis and Kidney Transplantation in Sudan. A Single Center Experience. Iran J Kidney Dis 4(4): 282284.

10. Karin S, Martin M, Carlsson P (2002) Comparison of Hemodialysis and Peritoneal Dialysis; a Cost-Utility Analysis. Peritoneal Dialysis International 22(1): 3947.

11. Peters TG, Kenneth $\mathrm{W}$ Jones, George $\mathrm{W}$ Walker, Ronald K Charlton, Laurel E Antonucci, et al. (1999) Living-unrelated kidney donation: a single center experience. Clinical Transplant 13: 108-112.

12. Raja Ramachandran, Vivekanand Jha (2013) Kidney Transplantation Is Associated with Catastrophic Out of Pocket Expenditure in India, PLoS One 8(7): e67812.

13. Laupacis A, Keown P, Pus N, Krueger H, Ferguson B, et al. (1996) A study of the quality of life and cost-utility of renal transplantation. Kidney Int 50(1): 235-242.

14. Churchill DN, Torrance GW, Taylor DW, Barnes CC, Ludwin D, et al. (1987) Measurement of quality of life in end-stage renal disease: the time trade off approach. Clin Invest Med 10(1): 141-120. 
15. The Euro Qol Group (1990) EuroQol-a new facility for the measurement of health-related quality of life. Health Policy 16(3): 199-208.

16. Cathrine E, Preben S, Karin Dam P (2014) In Denmark kidney transplantation is more costeffective than dialysis. Dan Med J 61(3): A4796.

17. Perović S, Janković S (2009) Renal transplantation vs hemodialysis: cost-effectiveness analysis; Vojnosanit Pregl 66(8): 639-644.

18. Jassal SV, Krahn MD, Naglie G, Zaltzman JS, Roscoe JM, et al. (2003) Kidney Transplantation in the Elderly: A Decision Analysis. J Am Soc Nephrol 14(1): 187-196.

19. Kute VB, Vanikar AV, Shah PR, Gumber MR, Patel HV, et al. (2014) Outcome of live and deceased donor renal transplantation in patients aged $\geq 55$ years: A single-center experience. Indian J Nephrol 24(1): 914.

20. Cheung K (2009) EQ-5D user guide: basic information on how to use EQ-5D. Version 2. Rotterdam: Euro Qol Group.

21. Garner TI, Dardis R (1989) Cost-effectiveness analysis of end-stage renal disease treatments. Med Care 25(1): 25-344.
22. Manns B, Brenda Hemmelgarn, Marcello Tonelli, Flora $\mathrm{Au}$, Carter Chiasson T, et al. (2010) Alberta Kidney Disease Network: Population based screening for chronic kidney disease: Cost effectiveness study. BMJ 341: c5869.

23. Haller M, Gutjahr G, Kramar R, Harnoncourt F, Oberbauer R (2011) Cost-effectiveness analysis of renal replacement therapy in Austria. Nephrol Dial Transplant 26(9): 2988-2995.

24. Klarenbach S, Tonelli M, Pauly R, Walsh M, Culleton B, et al. (2014) Economic Evaluation of Frequent Home Nocturnal Hemodialysis Based on a Randomized Controlled Trial. J Am Soc Nephrol 25(3): 587-594.

25. Shield CF, Jacobs RJ, Wyant S, Das A (1996) A costeffectiveness analysis of OKT3 induction therapy in cadaveric kidney transplantation. Am J Kidney Dis 27(6): 855-864.

26. Sullivan SD, Garrison LP Jr, Best JH (1997) The cost effectiveness of mycophenolate mofetil in the first year after primary cadaveric transplant. J Am Soc Nephrol 8(10): 1592-1598.

27. Tousignant P, Guttmann RD, Hollomby DJ (1985) Transplantation and home hemodialysis: their costeffectiveness. J Chronic Dis 38(7): 589-6015. 